\title{
Does a toothpaste containing blue covarine have any effect on bleached teeth? An in vitro, randomized and blinded study
}

Janaina Freitas BORTOLATTO(a) Andrea Abi Rached DANTAS(a) Ávery RONCOLATO(a) Hugo MERCHAN(a) Michael Christopher FLOROS(b) Milton Carlos KUGA(a) Osmir Batista de OLIVEIRA JUNIOR(a)

(a) Univ. Estadual Paulista - UNESP, School of Dentistry, Department of Restorative Dentistry, Araraquara, SP, Brazil.

(b) Trent University, Trent Center for Biomaterials Research, Departments of Physics \& Astronomy and Chemistry, Peterborough, ON, Canada.

Declaration of Interests: The authors certify that they have no commercial or associative interest that represents a conflict of interest in connection with the manuscript.

Corresponding Author: Andrea Abi Rached Dantas E-mail: aarached@yahoo.com.br

DOI: 10.1590/1807-3107BOR-2016.vol30.0033

Submitted: Jul 08, 2015

Accepted for publication: Nov 13, 2015

Last revision: Nov 24, 2015
Abstract: The objective of this study was to analyze the effect of bleaching toothpastes, both conventional and those containing the new whitening agent Blue Covarine, on teeth previously bleached by conventional techniques (in-office and at-home). Squared bovine enamel/dentin blocks $(6.0 \times 6.0 \times 2.0 \mathrm{~mm})$ were randomly distributed in 6 groups $(n=15)$, according to the technique used to bleach them (in-office: HP35\%; at-home: PC10\%) and the type of bleaching toothpaste (none: control; Blue Covarine containing: $\mathrm{BC}$; and without Blue Covarine: NBC). Experimental groups denominated HP35\%, HP35\%BC and HP35\%NBC received in-office tooth bleaching before toothbrushing, and groups $\mathrm{PC} 10 \%, \mathrm{PC} 10 \% \mathrm{BC}$ and $\mathrm{PC} 10 \% \mathrm{NBC}$ were subjected to at-home tooth bleaching prior to toothbrushing. After bleaching treatment, groups $\mathrm{HP} 35 \% \mathrm{BC}, \mathrm{PC} 10 \% \mathrm{BC}, \mathrm{HP} 35 \% \mathrm{NBC}$ and PC10\%NBC underwent daily tooth brushing in a brushing machine for 3 minutes (150 strokes/min, with a load of $375 \mathrm{~g}$ ). Tooth color alteration was measured by reflectance spectroscopy (Vita EasyShade, Vident, Brea, CA, USA) at: T0 (baseline) - after in-office or at-home bleaching treatment; T1 - immediately after tooth brushing; T2 - 7 days and T3 - 14 days after tooth brushing. Data was analyzed by repeated measures mixed ANOVA and the Bonferroni post hoc test, with a significance level of $5 \%$. Statistically significant differences were found between different experimental groups, evaluation times and for the interaction between them $(\mathrm{p}<0.001)$. Tooth brushing using either bleaching toothpaste (conventional or with Blue Covarine) showed no color alteration on teeth previously bleached by in-office and at-home tooth bleaching. The use of bleaching toothpastes on previously bleached teeth did not produce a color alteration.

Keywords: Tooth Bleaching; Bleaching Agents; Denture Cleansers; Dentifrices.

\section{Introduction}

The desire for whiter teeth is responsible for the rapid growth of tooth bleaching over the past decade and has led to the development of numerous techniques and products for this purpose. There are three main dental bleaching approaches: supervised at-home bleaching; in-office bleaching; 
and over-the-counter at-home bleaching products such as strips, mouthwashes and toothpastes. ${ }^{1,2}$ The first two techniques are based on the action of free radicals from the reaction of hydrogen peroxide or carbamide peroxide with the tooth structure. ${ }^{2,3}$ However, during the bleaching process, free radicals may cause adverse reactions, ${ }^{4,5,6,7}$ including trans and postoperative tooth sensitivity., ${ }^{7,9}$ The action of the over-the-counter products is based mostly on two mechanisms: bleaching of intrinsic stains using oxidizing agents to break down the organic molecules present in the tooth structure, and the removal and control of extrinsic stains through the action of abrasive agents.

Over-the-counter bleaching products usually have low levels of hydrogen peroxide $(3 \%-6 \%)$ and are self-applied to teeth once or twice per day for up to 14 days, depending on the dose and time of exposure. ${ }^{2}$ Bleaching toothpastes work by removing and/or controlling extrinsic staining by the action of optimized abrasives, surfactants, enzymes and polyphosphates..$^{10}$ These may be used in the maintenance and retouching techniques after at-home or in-office bleaching or with bleaching function and, in this case, they must be used regularly (for example, twice a day), and take 2-4 weeks for effects to begin to show. ${ }^{11}$

The International Commission on Illumination (CIE) in 1976 defined a tridimensional color space which provides a representation for color perception. The three axis are $L^{*}, a^{*}$ and $b^{*}$, where $L^{*}$ represents a measure of the object's luminosity and the axis $\mathrm{a}^{*}$ and $b^{*}$ represent chromaticity coordinates. ${ }^{12}$ Some tooth bleaching studies using peroxide based products have shown that the yellow-blue axis is the most important for bleaching color perception than a change in the axis $L^{*}$ and $a^{*}{ }^{13,14}$ Furthermore, a reduction of the $b^{*}$ value occurs more quickly and to a higher degree than changes to the $L^{*}$ values. ${ }^{15,16}$ Therefore, the $b^{*}$ component is the most important bleaching indicator.

This observation was applied in the development of a new bleaching toothpaste composed of modified silica and a blue pigment (Blue Covarine). ${ }^{17,18}$ The bleaching effect of Blue Covarine are based on modifying the perception of tooth color by depositing a thin blue film on the surface of the enamel (an optical effect). ${ }^{17}$
This toothpaste also contains a more effective abrasive system for the removal of extrinsic stains compared to other bleaching toothpastes based on silica. ${ }^{19}$ An in vitro study demonstrated that, after brushing extracted teeth with a Blue Covarine containing toothpaste, a film of Blue Covarine was deposited over tooth surface and shifted the yellow axis to the blue, providing a measurable and perceptible tooth bleaching effect. ${ }^{18}$

Clinical and laboratorial studies have shown toothpastes containing Blue Covarine produce immediate bleaching effects and have been suggested as a new approach for tooth whitening. ${ }^{17,18,20}$ However the effect of this toothpaste on previously bleached teeth has yet to be studied. Thus, this study evaluated the effect of a toothpaste containing Blue Covarine in teeth previously bleached by at-home and in-office techniques. The hypothesis to be tested is that the use of a toothpaste containing Blue Covarine promotes changes in the color of teeth which have previously been whitened by conventional bleaching techniques.

\section{Methodology}

\section{Study design}

This in vitro, controlled, randomized, paired and blinded study (examiner) used 90 bovine incisors selected according to the criteria that they are of similar color, have good structural integrity and have surface regularity. The dependent variable was color alteration $(\Delta \mathrm{E})$ and the independent variables were toothpaste (3 levels - without any toothpaste, toothpaste with Blue Covarine and toothpaste without Blue Covarine) and evaluation times (4 levels - T0, T1, T2 and T3). Evaluation times also led to a repeated measures variable.

\section{Samples preparation}

After prophylaxis, the bovine incisors had their roots removed using a low-speed, water-cooled diamond saw (Isomet 4000, Buehler Ltd., Lake Bluff, USA). Then, the teeth were sectioned in mesiodistal and cervical-incisal directions to obtain dental blocks of $6.0 \times 6.0 \times 2.0$ millimeters. The samples were numbered and randomly assigned to experimental groups by random drawing using Microsoft Excel 
2010 (Microsoft, Redmond, Washington, USA). The samples were then embedded in a neutral gray acrylic resin in sets of five teeth per resin block, which were coded and stored in artificial saliva under stirring at $36 \pm 1.0^{\circ} \mathrm{C}$ for a week prior to testing. The 18 experimental sets were randomly distributed in 6 experimental groups $(n=15)$, and were designated according to the bleaching technique used: in-office bleaching agent with 35\% hydrogen peroxide - HP35\% (Whiteness HP, FGM Produtos Odontológicos, Joinville, Brazil) or at-home bleaching agent using 10\% carbamide peroxide - CP10\% (Whiteness Perfect ${ }^{\circledR}$, FGM Produtos Odontológicos, Joinville, Brazil). The groups with also designated based on the toothpaste used: none (control), with Blue Covarine - BC (Close Up White Now, Unilever Brazil, São Paulo, Brazil) and without Blue Covarine - NBC (Colgate MaxWhite, Colgate Palmolive Brazil, São Paulo, Brazil). This resulted in a total of 6 groups: HP35\%, HP35\%BC, HP35\%NBC, $\mathrm{CP} 10 \%, \mathrm{CP} 10 \% \mathrm{BC}$ and $\mathrm{CP} 10 \% \mathrm{NBC}$.

\section{Bleaching Protocols}

Each group was submitted to the respective conventional bleaching technique, either in-office or at-home. The groups HP35\%, HP35\%BC and HP35\%NBC were bleached using a 35\% hydrogen peroxide in-office bleaching agent. The bleaching agent was prepared as recommended by the manufacturer. Two bleaching sessions were performed with a seven days interval between them. In each of the bleaching sessions, the bleaching agent was applied three times, and each application was $15 \mathrm{~min}$ in duration. After each session the sample sets were washed and placed in artificial saliva. The total time of contact of the bleaching agent with the dental enamel was 90 minutes.

The experimental groups CP10\%, CP10\%BC and $\mathrm{CP} 10 \% \mathrm{NBC}$ were treated by an at-home tooth bleaching agent containing $10 \%$ carbamide peroxide. For this purpose, individual trays were fabricated with $1 \mathrm{~mm}$ acetate plaques (Whiteness, FGM Produtos Odontológicos, Joinville, Brazil), standardizing a $1 \mathrm{~mm}$ thick bleaching gel on each dental block. The trays and the respective set were placed in a container with artificial saliva kept under gentle agitation and at a temperature of $36 \pm 1^{\circ} \mathrm{C}$ for 4 hours daily. Then, the bleaching agent was removed, the sets were washed in water and stored in artificial saliva. This procedure was repeated for 14 consecutive days, resulting in a total contact time of $3360 \mathrm{~min}$ between the bleaching gel and the dental structure.

After conventional bleaching, the groups $\mathrm{HP} 35 \% \mathrm{BC}$, $\mathrm{CP} 10 \% \mathrm{BC}, \mathrm{HP} 35 \% \mathrm{NBC}$ and $\mathrm{CP} 10 \% \mathrm{NBC}$ underwent toothbrushing in an automatic brushing machine (MAVTEC - Comércio e Serviços e Desenvolvimento para Laboratório, Ribeirão Preto, Brazil). The experimental sets were fixed in the machine and brushed with either a toothpaste containing Blue Covarine (groups HP35\%BC and CP10\%BC) or a control toothpaste without Blue Covarine (groups $\mathrm{HP} 35 \% \mathrm{NBC}$ and $\mathrm{CP} 10 \% \mathrm{NBC}$ ) in 3 brushing cycles, each 1 minute in duration, in order to simulate the toothbrushing standard recommended for patients ( 3 times per day, 1 minute each time). Toothpastes were previously mixed in distilled water and sodium carboxymethyl cellulose solution at $0.5 \%$ (CMCS), in a toothpaste:water:CMCS rate of 1:1:1, following a method adapted from Joiner et al..$^{10,17}$ The brushing test machine was programmed with a load of $375 \mathrm{~g}$ and a brushing rate of 150 strokes/min, resulting in a total of 450 strokes per set. After toothbrushing, the sets were washed in water to completely remove the toothpaste and stored in artificial saliva. The control group (C) did not received any treatment, and the samples remained in artificial saliva under stirring and controlled temperature $\left(36 \pm 1.0^{\circ} \mathrm{C}\right)$ during the experiment. The artificial saliva was changed once a week for all the groups.

\section{Tooth color evaluation}

The color alteration was measured with a reflectance spectrophotometer, the Vita EasyShade ${ }^{\circledR}$, Vident, Brea, USA by a blinded evaluator who was previously calibrated on the instrument. The examiner measured the color of 20 teeth at two different times, with a one week break between measurements. The calibration was calculated by the intraclass correlation coefficient (ICC). The ICC obtained was 0.74 , which is classified as good calibration. ${ }^{21}$

Tooth color was analyzed based on $\Delta \mathrm{L}, \Delta \mathrm{a}, \Delta \mathrm{b}$ and $\Delta \mathrm{E}$ coordinates from the CIELab color system. The 
measurements were performed at $\mathrm{T} 0$ (baseline) - after the conclusion of at-home or in-office tooth bleaching, T1 - immediately after toothbrushing, T2 - 7 days after toothbrushing, and T3 - 14 days after toothbrushing. In order to evaluate the effect of the different treatments on the color alteration, we considered the difference between the baseline color at $\mathrm{T} 0$ compared to the subsequent time measurements (T1, T2 and T3).

\section{Data analysis}

Data for color alteration $(\Delta \mathrm{E})$ and each CIELab color axis $\left(L^{*}, a^{*}\right.$ e $\left.b^{*}\right)$ were analyzed by a repeated measures mixed ANOVA. First, the conditions for the application of this test, namely the normal distribution, sphericity and homogeneity of variances were analyzed through the Shapiro-Wilk, Mauchly and Levene tests, respectively ( $\mathrm{p}<0.05)$. The Mauchly test indicated the need for the Greenhouse-Geisser correction $(\mathrm{p}<0.001)$. The Bonferroni test was used to identify which pairs of means differed for the interaction between the variables and experimental groups. All the statistical tests were performed with the assistance of PASW Statistics Software (PASW Statistics 21.0, SPSS Inc., Chicago, USA), considering a type I error probability (a) of 0.05 .

\section{Results}

each experimental group color characteristics $\left(\mathrm{L}^{*}, \mathrm{a}^{*}\right.$ and $\left.\mathrm{b}^{*}\right)$ at baseline - means \pm standard deviation (SD) - are shown in Table 1. Statistical analysis was performed for each outcome: color alteration $(\Delta \mathrm{E})$, luminosity $(\Delta \mathrm{L})$, alteration on the green-red axis $(\Delta \mathrm{a})$ and alteration on the blue-yellow axis $(\Delta \mathrm{b})$, as described below.

\section{Color alteration $(\Delta \mathrm{E})$}

The repeated measures mixed ANOVA showed significance for evaluation time $(\mathrm{p}<0.001)$ and for the interaction between evaluation time and experimental groups $(p=0.002)$. Differing experimental groups did not result in any differences $(p=0.107)$. The Bonferroni test evidenced significant differences between $\mathrm{CP} 10 \% \mathrm{NBC}$ at $\mathrm{T} 3$ and HP35\%, CP10\% and $\mathrm{CP} 10 \% \mathrm{BC}$ at $\mathrm{T} 1$ and $\mathrm{HP} 35 \% \mathrm{NBC}$ at $\mathrm{T} 1, \mathrm{~T} 2$ and $\mathrm{T} 3$. Means and respective confidence intervals $(95 \% \mathrm{CI})$ are illustrated in Table 2.

\section{Luminosity $(\Delta \mathrm{L})$}

Significance was found for the different experimental groups $(p=0.041)$, and for the interaction between experimental groups and evaluation time $(p<0.001)$.

Table 1. Means and standard deviation $( \pm S D)$ of the baseline color characteristics for each experimental group.

\begin{tabular}{|c|c|c|c|c|c|c|c|c|c|}
\hline \multirow{2}{*}{ Experimental group } & \multicolumn{3}{|c|}{$L^{*}$} & \multicolumn{3}{|c|}{$a^{*}$} & \multicolumn{3}{|c|}{$b^{*}$} \\
\hline & mean & \pm & sd & mean & \pm & sd & mean & \pm & sd \\
\hline HP35\% & 84.3 & \pm & 3.8 & 0.5 & \pm & 2.6 & 11.2 & \pm & 4.0 \\
\hline CP10\% & 86.8 & \pm & 2.6 & -3.1 & \pm & 1.3 & 7.0 & \pm & 4.4 \\
\hline HP35\%BC & 81.8 & \pm & 6.7 & 3.1 & \pm & 5.1 & 11.0 & \pm & 3.9 \\
\hline СР10\%BC & 85.0 & \pm & 6.4 & 1.3 & \pm & 3.7 & 7.5 & \pm & 3.3 \\
\hline HP35\%NBC & 84.6 & \pm & 3.3 & -3.2 & \pm & 1.2 & 9.9 & \pm & 3.3 \\
\hline CP10\%NBC & 86.9 & \pm & 3.2 & 1.1 & \pm & 3.7 & 6.6 & \pm & 3.0 \\
\hline
\end{tabular}

*Different letters means significant differences $(p<0.05)$.

Table 2. Mean and Confidence interval $(95 \% \mathrm{Cl})$ for color alteration $(\Delta \mathrm{E})$ for each experimental group at each evaluation time.

\begin{tabular}{|c|c|c|c|c|c|c|c|c|c|c|c|c|}
\hline \multirow{3}{*}{ Evaluation time } & \multicolumn{12}{|c|}{ Experimental group } \\
\hline & \multicolumn{2}{|c|}{ HP35\% } & \multicolumn{2}{|c|}{ СР10\% } & \multicolumn{2}{|c|}{ HP35\%BC } & \multicolumn{2}{|c|}{ СР10\%BC } & \multicolumn{2}{|c|}{ HP35\%NBC } & \multicolumn{2}{|c|}{$\mathrm{CP} 10 \% \mathrm{NBC}$} \\
\hline & mean* & $95 \% \mathrm{Cl}$ & mean* & $95 \% \mathrm{Cl}$ & mean* & $95 \% \mathrm{Cl}$ & mean* & $95 \% \mathrm{Cl}$ & mean* & $95 \% \mathrm{Cl}$ & mean* & $95 \% \mathrm{Cl}$ \\
\hline $\mathrm{T} 1$ & $3.0 \mathrm{bc}$ & 1.1 & $2.5 \mathrm{bc}$ & 1.1 & $4.9 a b$ & 1.1 & $3.6 \mathrm{~b}$ & 1.1 & $3.4 b$ & 1.1 & $4.6 a b$ & 1.1 \\
\hline T2 & $4.6 \mathrm{ab}$ & 1.1 & $4.9 \mathrm{ab}$ & 1.1 & $5.0 \mathrm{ab}$ & 1.1 & $4.4 \mathrm{ab}$ & 1.1 & $3.4 \mathrm{~b}$ & 1.1 & $4.8 \mathrm{ab}$ & 1.1 \\
\hline T3 & $4.6 \mathrm{ab}$ & 1.1 & $4.9 \mathrm{ab}$ & 1.1 & $4.2 \mathrm{ab}$ & 1.1 & $5.4 \mathrm{ab}$ & 1.1 & $3.3 b$ & 1.1 & $6.2 \mathrm{a}$ & 1.1 \\
\hline
\end{tabular}

*Different letters means significant differences $(p<0.05)$. 
Statistically significant difference between CP10\% and $\mathrm{HP} 35 \% \mathrm{BC}$ at $\mathrm{T} 1$ and $\mathrm{T} 4$ as well as HP35\%NBC at $\mathrm{T} 2$ and $\mathrm{T} 3$ were found. Table 3 shows the means and confidence intervals $(95 \% \mathrm{CI})$.

\section{Green-Red axis $(\Delta a)$}

The ANOVA analysis demonstrated a statistically significant difference only for the experimental groups $(p<0.001)$. The Bonferroni method found significance between the HP35\% and HP35\%BC and the group CP10\%NBC. Means and confidence intervals $(95 \% \mathrm{CI})$ are shown in Table 4.

\section{Blue-Yellow axis $(\Delta b)$}

The repeated measures mixed ANOVA found significant differences for the evaluation time $(\mathrm{p}<0.001)$, experimental group $(p<0.001)$ and the interaction of factors $(p<0.001)$. The Bonferroni method demonstrated that $\mathrm{CP} 10 \% \mathrm{NBC}$ at $\mathrm{T} 2$ and $\mathrm{T} 3$ were different than $\mathrm{HP} 35 \%$ at $\mathrm{T} 1$ and $\mathrm{HP} 35 \% \mathrm{BC}$ at $\mathrm{T} 1$ and $\mathrm{T} 2$. Table 5 shows the means and confidence intervals $(95 \% \mathrm{CI})$.

\section{Discussion}

This study evaluated the effects of bleaching toothpastes with or without Blue Covarine on the color alteration of teeth previously bleached by at-home and in-office tooth bleaching techniques. These bleaching toothpastes were compared with control groups which only received bleaching by conventional techniques (HP35\% and CP10\%) and were not treated with bleaching toothpastes.

The $L^{*}, a^{*}$ and $b^{*}$ parameters at baseline (Table 1) show similar bleaching results for all 6 experimental groups, regardless of the bleaching agent used (at-home or in-office tooth bleaching). As previously demonstrated, these results also

Table 3. Mean and Confidence intervals $(95 \% \mathrm{Cl})$ of luminosity $(\Delta \mathrm{L})$ for each group during all evaluation times.

\begin{tabular}{|c|c|c|c|c|c|c|c|c|c|c|c|c|}
\hline \multirow{3}{*}{ Evaluation time } & \multicolumn{12}{|c|}{ Experimental group } \\
\hline & \multicolumn{2}{|c|}{ HP35\% } & \multicolumn{2}{|c|}{ СР10\% } & \multicolumn{2}{|c|}{ HP35\%BC } & \multicolumn{2}{|c|}{$\mathrm{CP} 10 \% \mathrm{BC}$} & \multicolumn{2}{|c|}{ HP35\%NBC } & \multicolumn{2}{|c|}{ CP10\%NBC } \\
\hline & mean* & $95 \% \mathrm{Cl}$ & mean* & $95 \% \mathrm{Cl}$ & mean* & $95 \% \mathrm{Cl}$ & mean* & $95 \% \mathrm{Cl}$ & mean* & $95 \% \mathrm{Cl}$ & mean* & $95 \% \mathrm{Cl}$ \\
\hline $\mathrm{T1}$ & $-1.5 a b$ & 1.5 & $-1.8 a b$ & 1.5 & $-1.4 a b$ & 1.5 & $-2.5 a b$ & 1.5 & $-1.4 a b$ & 1.5 & $-3.3 a b$ & 1.5 \\
\hline T2 & $-2.7 a b$ & 1.5 & $-4.4 b$ & 1.5 & $-0.8 a b$ & 1.5 & $-1.6 a b$ & 1.5 & $-1.1 \mathrm{ab}$ & 1.5 & $-1.7 a b$ & 1.5 \\
\hline T3 & $-2.7 a b$ & 1.5 & $-4.4 b$ & 1.5 & $-2.5 a b$ & 1.5 & $-1.3 a b$ & 1.5 & $0.3 a$ & 1.5 & $-3.7 b$ & 1.5 \\
\hline
\end{tabular}

*Different letters means significant differences $(p<0.05)$.

Table 4. Means and Confidence intervals $(95 \% \mathrm{Cl})$ for $\Delta \mathrm{a}$ for each experimental group at all evaluation times.

\begin{tabular}{|c|c|c|c|c|c|c|c|c|c|c|c|c|}
\hline \multirow{3}{*}{ Evaluation time } & \multicolumn{12}{|c|}{ Experimental groups } \\
\hline & \multicolumn{2}{|c|}{ HP35\% } & \multicolumn{2}{|c|}{ СР10\% } & \multicolumn{2}{|c|}{ HP35\%BC } & \multicolumn{2}{|c|}{$\mathrm{CP} 10 \% \mathrm{BC}$} & \multicolumn{2}{|c|}{ HP35\%NBC } & \multicolumn{2}{|c|}{$\mathrm{CP} 10 \% \mathrm{NBC}$} \\
\hline & mean* & $95 \% \mathrm{Cl}$ & mean* & $95 \% \mathrm{Cl}$ & mean* & $95 \% \mathrm{Cl}$ & mean* & $95 \% \mathrm{Cl}$ & mean* & $95 \% \mathrm{Cl}$ & mean* & $95 \% \mathrm{C}$ \\
\hline $\mathrm{T1}$ & $-1.1 b$ & 0.5 & $-0.4 a b$ & 0.5 & $-1.7 b c$ & 0.5 & $0.1 \mathrm{ab}$ & 0.5 & $-0.5 a b$ & 0.5 & $0.0 a$ & 0.5 \\
\hline T2 & $-1.4 b$ & 0.6 & $-0.2 a b$ & 0.6 & $-2.0 b c$ & 0.6 & $-0.5 a b$ & 0.6 & $-0.2 a b$ & 0.6 & $0.2 a$ & 0.6 \\
\hline T3 & $-1.4 b$ & 0.6 & $-0.2 a b$ & 0.6 & $-1.6 b c$ & 0.6 & $-0.5 a b$ & 0.6 & $-0.1 a b$ & 0.6 & $0.3 a$ & 0.6 \\
\hline
\end{tabular}

*Different letters means significant differences $(p<0.05)$.

Table 5. Mean and Confidence intervals $(95 \% \mathrm{Cl})$ of $\Delta b$ for each experimental group at each evaluation time.

\begin{tabular}{|c|c|c|c|c|c|c|c|c|c|c|c|c|}
\hline \multirow{3}{*}{ Evaluation time } & \multicolumn{12}{|c|}{ Experimental groups } \\
\hline & \multicolumn{2}{|c|}{ HP35\% } & \multicolumn{2}{|c|}{ СР10\% } & \multicolumn{2}{|c|}{ HP35\%BC } & \multicolumn{2}{|c|}{ СР10\%BC } & \multicolumn{2}{|c|}{ HP35\%NBC } & \multicolumn{2}{|c|}{ CP10\%NBC } \\
\hline & mean* & $95 \% \mathrm{Cl}$ & mean* & $95 \% \mathrm{Cl}$ & mean* & $95 \% \mathrm{Cl}$ & mean* & $95 \% \mathrm{Cl}$ & mean* & $95 \% \mathrm{Cl}$ & mean* & $95 \% \mathrm{Cl}$ \\
\hline $\mathrm{T1}$ & $-1.1 c$ & 1.2 & $0.5 b c$ & 1.2 & $-2.5 c$ & 1.2 & $1.2 \mathrm{ab}$ & 1.2 & $-0.7 b c$ & 1.2 & $1.4 \mathrm{ab}$ & 1.2 \\
\hline $\mathrm{T} 2$ & $0.4 \mathrm{bc}$ & 1.2 & $1.0 \mathrm{ab}$ & 1.2 & $-1.1 c$ & 1.2 & $2.6 a b$ & 1.2 & $-0.5 b c$ & 1.2 & $3.4 \mathrm{a}$ & 1.2 \\
\hline T3 & $0.4 \mathrm{bc}$ & 1.2 & $1.0 \mathrm{ab}$ & 1.2 & $1.2 \mathrm{ab}$ & 1.2 & $2.5 a b$ & 1.2 & $1.1 \mathrm{ab}$ & 1.2 & $2.9 a$ & 1.2 \\
\hline
\end{tabular}

*Different letters means significant differences $(p<0.05)$. 
evidence similar bleaching efficacy after two weeks of treatment for both at-home and in-office bleaching techniques using carbamide peroxide and hydrogen peroxide, respectively. ${ }^{22,23}$

An in vivo study by Collins et al. ${ }^{20}$ has demonstrated that a single toothbrushing with a toothpaste containing Blue Covarine provided a significate and immediate reduction on $\mathrm{b}^{*}$ axis (yellow-blue) and an increase on WIO index, compared to the baseline and to a control toothpaste containing silica. Joiner et al. ${ }^{17}$ also identified toothpastes containing Blue Covarine as a new approach for tooth bleaching due to a reduction of $\Delta b$ values generated by this toothpaste in their study. These results were not demonstrated in this study and the use of the toothpaste containing Blue Covarine did not display any color alteration. This may be due to the fact that previous studies using Blue Covarine containing toothpastes measured the color by digital image analysis and, in our study, we used a reflectance spectrophotometer. Torres et al. ${ }^{24}$ found no significant results of $\Delta \mathrm{E}, \Delta \mathrm{L}$ and $\Delta \mathrm{b}$ for the toothpaste containing Blue Covarine when analyzing the color with the aid of a spectrophotometer. The reflectance spectrophotometer analyzes the color of teeth, ceramics and other translucent materials and is configured to analyze the dentin and deep enamel color, ignoring the reflection and surface irregularities..$^{25}$ For this reason, it's possible that this device cannot capture the presence of the thin Blue Covarine film on the surface of the samples, nor any visible optical effects caused by this coating.

After toothbrushing with the bleaching toothpastes with or without Blue Covarine, the maintenance of color alteration $(\Delta \mathrm{E})$ was observed and recorded by measurements immediately after, 7 days after and 14 days after brushing for the groups previously bleached by the in-office technique. The groups bleached by the at-home technique showed progressive increases in $\triangle \mathrm{E}$ values, although only the CP10\%NBC group obtained statistically significant differences at $\mathrm{T} 3$. This fact does not prove the effectiveness of toothpastes with or without Blue Covarine, but does indicate that the at-home bleaching continues to change the color of the teeth even 14 days after the end of treatment.

For $\Delta \mathrm{L}$, there was a tendency to lose luminosity over time, with the axis displacement shifting towards black. Only CP10\%BC and HP35\%NBC showed shifts toward white, which may indicate better interaction of the toothpaste containing Blue Covarine with teeth bleached by carbamide peroxide while the toothpaste without Blue Covarine interacts better with hydrogen peroxide. The $\mathrm{a}^{*}$ axis showed a greater shift toward the green axis immediately after brushing in the HP35\%BC group, but no significant difference was found for the HP35\% group. These results were maintained over time and were significantly different than the results of $\mathrm{CP} 10 \% \mathrm{NBC}$, showing a progressive shift towards red. The $b^{*}$ axis also demonstrates a shift towards yellow over time for all groups. Immediately after brushing, although not statistically significant, the HP35\%BC showed the greatest change in the blue direction and this effect can be observed up to 7 days after brushing. However, the same cannot be said for $\mathrm{CP} 10 \% \mathrm{BC}$ and no definitive bleaching effect of toothpaste containing Blue Covarine was demonstrated.

Considering the results discussed herein, the hypothesis of this study can be rejected. No statistically significant bleaching were achieved on teeth previously bleached by in-office or at-home bleaching techniques when using a conventional bleaching toothpaste or a bleaching toothpaste containing Blue Covarine.

\section{Conclusion}

Within the limitations of this in vitro study, it can be concluded that the use of conventional bleaching toothpastes and bleaching toothpastes containing Blue Covarine do not show an improvement in whitening teeth which have already been treated with at-home and in-office conventional tooth bleaching protocols using either $10 \%$ carbamide peroxide or $35 \%$ hydrogen peroxide, respectively. 


\section{References}

1. Heymann HO. Tooth whitening: facts and fallacies. Br Dent J. 2005;198(8):514. doi:10.1038/sj.bdj.4812298

2. Joiner A. The bleaching of teeth: a review of the literature. J Dent. 2006;34(7):412-9. doi:10.1016/j.jdent.2006.02.002

3. Joiner A. Review of the effects of peroxide on enamel and dentine properties. J Dent. 2007;35(12):889-96. doi:10.1016/j.jdent.2007.09.008

4. Trindade FZ, Ribeiro APD, Sacono NT, Oliveira CF, Lessa FCR, Hebling J, et al. Trans-enamel and trans-dentinal cytotoxic effects of a $35 \% \mathrm{H} 2 \mathrm{O} 2$ bleaching gel on cultured odontoblast cell lines after consecutive applications. Int Endod J. 2009;42(6):516-24. doi:10.1111/j.1365-2591.2009.01544.x. Erratum in: Int Endod J. 2009 Jul;42(7):649.

5. Ribeiro APD, Sacono NT, Lessa FCR, Nogueira I, Coldebella $\mathrm{CR}$, Hebling J, et al. Cytotoxic effect of a 35\% hydrogen peroxide bleaching gel on odontoblast-like MDPC-23 cells. Oral Surg Oral Med Oral Pathol Oral Radiol Endod. 2009;108(3):458-64. doi:10.1016/j.tripleo.2009.05.006

6. Costa CAS, Riehl H, Kina JF, Sacono NT, Hebling J. Human pulp responses to in-office tooth bleaching. Oral Surg Oral Med Oral Pathol Oral Radiol Endod. 2010;109(4):e59-e64. doi:10.1016/j.tripleo.2009.12.002

7. Dahl JE, Pallesen U. Tooth bleaching: a critical review of the biological aspects. Crit Rev Oral Biol Med. 2003;14(4):292-304. doi:10.1177/154411130301400406

8. Goldberg M, Grootveld M, Lynch E. Undesirable and adverse effects of tooth-whitening products: a review. Clin Oral Investig. 2010;14(1):1-10. doi:10.1007/s00784-009-0302-4

9. Markowitz K. Pretty painful: why does tooth bleaching hurt? Med Hypotheses. 2010;74(5):835-40. doi:10.1016/j.mehy.2009.11.044

10. Joiner A. Whitening toothpastes: a review of the literature. J Dent. 2010;38(Suppl 2):e17-24. doi:10.1016/j.jdent.2010.05.017

11. Joiner A. The cleaning of teeth. In: Johansson I, Somasundaran $\mathrm{P}$, editors. Handbook for cleaning/decontamination of surfaces. [place unknown]: Elsevier; 2007. p. 371-405.

12. Joiner A. Tooth colour: a review of the literature. J Dent. 2004;32(Suppl 1):3-12. doi:10.1016/j.jdent.2003.10.013

13. Gerlach RW, Barker ML, Sagel PA. Objective and subjective whitening response of two self-directed bleaching systems. Am J Dent. 2002;15(Spec No):7A-12A.
14. Gerlach RW, Gibb RD, Sagel PA. A randomized clinical trial comparing a novel $5.3 \%$ hydrogen peroxide whitening strip to $10 \%, 15 \%$, and $20 \%$ carbamide peroxide tray-based bleaching systems. Compend Contin Educ Dent Suppl. 2000;(29):S22-8; quiz S42-3.

15. Kleber CJ, Putt MS, Nelson BJ. In vitro tooth whitening by a sodium bicarbonate/peroxide dentifrice. J Clin Dent. 1997;9(1):16-21.

16. Goodson JM, Tavares M, Sweeney M, Stultz J, Newman M, Smith V, et al. Tooth whitening: Tooth color changes following treatment by peroxide and light. J Clin Dent. 2004;16(3):78-82.

17. Joiner A, Philpotts CJ, Alonso C, Ashcroft AT, Sygrove NJ. A novel optical approach to achieving tooth whitening. J Dent. 2008;36(Suppl 1):S8-14.

18. Joiner A. A silica toothpaste containing blue covarine: a new technological breakthrough in whitening. Int Dent J. 2009;59(5):284-8.

19. Joiner A, Philpotts CJ, Ashcroft AT, Laucello M, Salvaderi A. In vitro cleaning, abrasion and fluoride efficacy of a new silica based whitening toothpaste containing blue covarine. J Dent. 2008;36(Suppl 1):S32-7. doi:10.1016/j.jdent.2008.02.003

20. Collins LZ, Naeeni M, Platten SM. Instant tooth whitening from a silica toothpaste containing blue covarine. J Dent. 2008;36(Suppl 1):S21-5. doi:10.1016/j.jdent.2008.02.006

21. Fermanian J. Mesure de l'accord entre deux juges: cas quantitatif. Rev Epidemiol Sante Publique. 1984;32(6):408-13.

22. Tay LY, Kose C, Herrera DR, Reis A, Loguercio AD. Longterm efficacy of in-office and at-home bleaching: a 2-year double-blind randomized clinical trial. Am J Dent. 2012;25(4):199-204.

23. Mondelli RFL, Azevedo JFDG, Francisconi AC, Almeida CM, Ishikiriama SK. Comparative clinical study of the effectiveness of different dental bleaching methods-two year follow-up. J Appl OralSci. 2012;20(4):435-43. doi:10.1590/S1678-77572012000400008

24. Torres CRG, Perote LCCC, Gutierrez NC, Pucci CR, Borges AB. Efficacy of mouth rinses and toothpaste on tooth whitening. Oper Dent. 2013;38(1):57-62. doi:10.2341/11-360-L

25. Luo W, Westland S, Brunton P, Ellwood R, Pretty IA, Mohan $\mathrm{N}$. Comparison of the ability of different colour indices to assess changes in tooth whiteness. J Dent. 2007;35(2):109-16. doi:10.1016/j.jdent.2006.06.006 